\title{
COMO ADMINISTRAR CUIDADOS DOMICILIARES: \\ O CUSTO E O PREÇO DO PREPARO E DO TRABALHO DA ENFERMAGEM - UMA EXPERIÊNCIA
}

\author{
How to Manage Home-Care Service: The Cost and Price of the \\ Training and the Work of the Nursing Professional - An Experience \\ Como Administrar Cuidados Domiciliares: El Costo y el Precio de la \\ Preparación y del Trabajo de la Enfermería - Una Experiencia
}

Vivian Schutz

Joséte Luzia Leite

Nébia Maria Almeida de Figueiredo

\section{Resumo}

Relato de experiência sobre o custo da administração de cuidados domiciliares, considerando a seleção, treinamento e supervisão do profissional. A questão norteadora baseou-se no custo da administração do cuidado domiciliar em uma instituição, que prepara os profissionais de enfermagem para realizar os cuidados. Seus objetivos foram: relatar o custo da seleção e treinamento de pessoal de enfermagem para o cuidado domiciliar; e discutir o processo de administrar os cuidados domiciliares com destaque para as facilidades e dificuldades que os profissionais de enfermagem encontram para que a assistência domiciliar seja realizada. Como metodologia foi usado o relato de atividades desenvolvidas por uma empresa que presta serviços para que sejam realizados os cuidados domiciliares. Como resultados foram elaboradas três categorias: estratégias de recrutamento e custo da seleção dos profissionais de enfermagem para a assistência domiciliar; custos com o treinamento do pessoal selecionado para assistência domiciliar; e alocação dos profissionais treinados no mercado de cuidados domiciliares e particulares. Para a realização de uma adequada assistência domiciliar, conclui-se que é necessário contar com bons profissionais de enfermagem e, para que isso ocorra, deve-se treiná-los adequadamente após o seu recrutamento e seleção.

Palavras-chave: Custos e Análise de Custo. Economia da Enfermagem.

\begin{abstract}
Experience report about the cost of the administration of domiciliary care, considering the selection, training and supervision of the professional. The guide question was based in the cost to supervise professionals that will provide home care service for an Institution. Its objectives are: to report the cost of the selection and training of the Nursing professionals to the domiciliary care; and to discuss the process of the domiciliary care management emphasizing the facilities and difficulties found by the nursing professionals when realize the domiciliary assistance. As methodology was used the report of activities developed by an enterprise that gives services that could be realized the domiciliary care. As results was elaborated three categories: strategies of recruiting and cost of the selection of the nursing professionals to the domiciliary assistance; costs with the training of the personal selected to the domiciliary assistance; distribution of the professionals trained in the market of domiciliary and particular care. For the realization of an adequate domiciliary assistance, was concluded that is necessary to be supported by good nursing professionals, and, in order to this occurs, it must, after his recruitment and selection, train them adequately.
\end{abstract}

Keywords:

Cost and Cost Analysis. Economics, Nursing.

\section{Resumen}

Relato de experiencia sobre el custo de la administración de los cuidados domiciliares, considerando la selección, entrenamiento y supervisión del profesional. La cuestión norteadora del estudio fué basada en la custo de la administración del cuidado domiciliar en una institución preparadora de profesionales para la realización de los cuidados. Sus objetivos fueron: Relatar el custo de la selección y entrenamiento de personal de Enfermería para el cuidado domiciliar; y discutir el proceso de administrar los cuidados domiciliares con evidencia en las facilidades y dificultades que los profesionales de enfermería encuentran para que la ayuda domiciliar sea realizada. Como metodología fue usado el relato de actividades desarrolladas por una empresa que presta servicios para que sean realizados los cuidados domiciliares. Como resultados fueron elaboradas tres categorías: estrategias de reclutamiento y custo de la selección de los profesionales de enfermería para la ayuda domiciliar; custos con el entrenamiento del personal seleccionado para ayuda domiciliar; distribución de los profesionales entrenados en el mercado de cuidados domiciliares y particulares. Para la realización de una adecuada ayuda domiciliar, concluyese que se hace necesario contar con buenos profesionales de enfermería, y, para que eso ocurra, se debe, después de su reclutamiento y selección, entrenarlos adecuadamente.

Palabras clave:

Costos y Análisis de Costo. Economía de la Enfermería. 
INTRODUÇÃO

\section{O Tema e sua Abrangência}

Os diversos modos de pensar a saúde devem ser sempre uma das prioridades, não só do país, mas dos profissionais da área que estão cuidando das pessoas nos diversos cenários onde os clientes se encontram, e, neste trabalho, em especial dos profissionais de enfermagem.

Normalmente, as preocupações estão concentradas dentro dos hospitais e/ou unidades de saúde, quando, na atualidade, existe um movimento significativo para cuidar das famílias através das políticas de saúde - PSF (Programa de Saúde da Família) e Assistência Domiciliar (Home Care), este mais especificamente para clientes de classe média alta ou para aqueles a quem o seguro-saúde paga.

Pensar nessas novas abordagens de cuidar em saúde é acreditar que é possível, no Brasil, investir no Mercado da Assistência Domiciliar como uma forma poderosa de reduzir gastos com a saúde, ampliando, assim, o campo de assistência aliada a mais conforto para os clientes. Este mais recente serviço de saúde é capaz de romper os limites da internação hospitalar, permitindo que sua estrutura convencional se transfira para um ambiente no qual o cliente provavelmente se sinta melhor: sua própria residência. Dependendo do cliente e de suas condições, ele não necessita apenas de visitas domiciliares, mas de cuidados diretos, e, para isso, é preciso ter pessoal capaz de cuidar dele, durante o dia e a noite.

Assim, essas formas de ação se concentram em dois modos de atuar: uma através do PSF e outra através da Assistência Domiciliar. Neste momento, este estudo teórico-prático está centrado no cuidado domiciliar, entendido como um serviço que é mais particular do que público pela sua natureza econômica e, também, pela sua crescente necessidade. Porém, é necessário pensar no treinamento destes profissionais de enfermagem que optam pelo cuidado em casa. Assim, estarão atuando em novos territórios de ação. A Enfermagem, por estar, na maioria das vezes, em freqüente contato com os clientes na residência, seja através de plantões, visitas domiciliares ou atendimento domiciliar, deve, dentre as demais profissões, exercer o maior controle, conhecimento e domínio de tudo o que acontece neste ambiente. Ela se torna fundamental na Assistência Domiciliar desde sua coordenação à simples orientação ou informação que devam ser realizadas. É o enfermeiro quem administra os cuidados prestados aos clientes nas mais diversas formas e funções.

Administrar cuidados no domicílio e quanto custa fazer isto é o nosso objeto de reflexão e de registro desta experiência. Portanto, torna-se indispensável pensar, também, no preço do trabalho destes profissionais, não só quanto ao cuidado que fazem diretamente ao cliente, mas quanto custa administrar uma empresa de profissionais de enfermagem preparando, treinando e acompanhando-os para cuidar no domicílio. Neste sentido, é válido questionar: Quanto custa a administração do cuidado domiciliar em uma instituição que prepara os profissionais de enfermagem para realizar os cuidados?
Assim, elaboramos os seguintes objetivos:

- Relatar o custo da seleção e treinamento de pessoal de enfermagem para o cuidado domiciliar;

- Discutir o processo de administrar os cuidados domiciliares, com destaque para as facilidades e dificuldades que os profissionais de enfermagem encontram para que a assistência domiciliar seja realizada.

0 estudo se justifica pelo fato de que cuidar em casa é uma realidade mundial que tem objetivos diversos, como: diminuir custos hospitalares, evitar infecções hospitalares, proporcionar conforto e segurança ao cliente e à família, manter sua intimidade, assim como seu papel social e familiar, e manter suas atividades ocupacionais. Crescem, a cada dia, as perspectivas de desenvolvimento nesta área de atuação como as pesquisas no domicílio, os prontuários digitalizados pessoais dos clientes e uma rede de sistema de referência e contrareferência. Estas também têm o intuito de mostrar vantagens para a equipe de enfermagem, como expandir suas possibilidades de trabalho, trabalhar de forma individualizada, trabalhar em equipe multiprofissional, mantendo constante atualização.

\section{Contextualização da Assistência Domiciliar: o Que É, Quem Faz e Quanto Custam o Preparo e o Trabalho}

0 termo Assistência Domiciliar vem sendo utilizado para englobar as seguintes modalidades':

Visita Domiciliar - seria aquele contato do profissional da saúde com a população de risco, com o indivíduo ou seus familiares no intuito de coletar informações ou de realizar algumas orientações visando à prevenção de doenças e promoção da saúde.

Atendimento Domiciliar - já considerado um componente do cuidado por meio dos quais os serviços de saúde são oferecidos ao indivíduo e/ou sua família na residência, em caráter preventivo ou assistencial.

Internação Domiciliar - é a transferência do indivíduo do hospital para a residência, onde existam todos os recursos hospitalares conforme suas necessidades, traduzidas em recursos técnicos e humanos.

Assistência Domiciliar à Saúde ${ }^{1}$ é a provisão de serviços de saúde às pessoas de qualquer idade, em casa ou em outro local não institucional. Ela começa com o cliente, indivíduo identificado como necessitado dos cuidados de enfermagem ou algum tipo de terapia.

Mas, seja qual for a forma de assistência necessária, mais ou menos intervencionista, os profissionais de enfermagem necessitam ser capacitados especificamente para um tipo de atendimento distinto do hospitalar e ambulatorial tradicionais.

0 cuidado domiciliar vem como uma alternativa para retirar precocemente o cliente do ambiente hospitalar, reduzindo, com isso, o custo institucional e melhorando a humanização ao cliente e família. Este cuidado vem se tornando mais fácil com a alta tecnologia de equipamentos e materiais para o uso no domicílio.

A Assistência Domiciliar requer do profissional de saúde um aprendizado para lidar com situaç̃̃es novas. Na instituição de saúde, o cliente está sozinho, na maioria das vezes, e tem que se adaptar às normalizações da instituição, seus hábitos, horários, costumes, tipos de alimentação, espaço físico, muitas 
vezes restrito, e tendo que estabelecer interação com pessoas desconhecidas. Por outro lado, os profissionais se encontram em "seu ambiente" e, de certa forma, estão eticamente protegidos pela instituição.

Quando se instala a Assistência Domiciliar, este quadro muda. 0 profissional muitas vezes convive apenas com aquele indivíduo e sua família, com suas crenças, costumes e valores. Ao contrário da situação anterior, o cliente está em seu ambiente, podendo ser ele mesmo em sua plenitude, com seu espaço preservado.

0 enfermeiro tem sido a chave na Assistência Domiciliar, desde o processo de elegibilidade dos clientes para a internação no domicílio à adequação dos modelos domiciliários a serem adotados. 0 que envolve planejamento, coordenação, treinamento, avaliação dos cuidados realizados pelos demais profissionais da área, incluindo o controle dos gastos na assistência domiciliar. Ele integra a promoção da saúde e a abordagem dos fatores ambientais, psicossociais, econômicos, culturais, religiosos e pessoais da saúde que afetam o bemestar do indivíduo e de sua família.

Assim, uma outra base da Assistência Domiciliar é a importância de termos conhecimentos acerca de economia, quando tem sido afirmado que o nosso dia-a-dia ${ }^{2}$, independentemente de sermos consumidores, trabalhadores, produtores ou cidadãos, nos conduz nos a questões econômicas, seja no âmbito nacional, regional ou local, sobre a formação de preços, o mercado de trabalho, o papel do governo e assim por diante. Como afirma Alfred Marshall, a economia é o estudo do homem nos negócios diários da sua vida (Mendes ${ }^{2}$ ). No caso da Enfermagem, seu negócio é o cuidado com que realizamos as inúmeras tarefas diárias que temos sob nossa responsabilidade, mas também, tem que ser pensado em quanto custa esse nosso trabalho para a empresa e quanto este vale em preço, questões que temos convivido freqüentemente e que somente com os conceitos sobre economia poderemos respondê-las. Para isto, trazemos aqui algumas definições consideradas básicas e importantes dentro da área econômica.

A expressão custos ${ }^{2}$ pode assumir diferentes conotações, dependendo do contexto em que é empregada. Se, por exemplo, entramos em uma farmácia e afirmamos que um pacote de gaze custou para nós $R \$ 0,50$, está claro que pagamos este valor por ele. A compreensão desta afirmação é imediata. No caso, porém, de a pergunta ser sobre quais foram os custos desta gaze para 0 dono da farmácia, diferentes interpretações e respostas poderão ser obtidas. 0 dono poderia pensar no conceito acerca dos custos financeiros para comercializar esta gaze, ou seja, o que teve que gastar até esta gaze chegar na prateleira para o consumidor.

Mas de uma forma geral, custos $^{3}$ podem ser definidos como medidas monetárias dos sacrifícios, como forma de investimento, com os quais uma organização tem que arcar a fim de atingir seus objetivos. Por exemplo, para que uma empresa de Assistência Domiciliar funcione, necessita de um enfermeiro responsável por ela, um coordenador de enfermagem, que deve ser contratado mesmo antes de iniciar o negócio. É obvio que a empresa deverá arcar com os custos deste profissional até que consiga repor o dinheiro investido, o que é esperado após o início de suas atividades no mercado.
Estes custos poderiam ser os salários (encargos trabalhistas), como o Instituto Nacional de Seguridade Social (INSS), Fundo de Garantia por Tempo de Serviço (FGTS), Férias, entre outros (encargos sociais). Tudo isto se faz necessário para que a empresa comece a funcionar, e são estes os custos que a empresa teria que arcar com este profissional.

Preços $^{3}$, por sua vez, correspondem à importância recebida pelas entidades em decorrência da oferta de seus produtos ou serviços. Deve ser suficiente o bastante para cobrir todos os custos incorridos, e ainda fornecer um lucro para a entidade. Ainda com o mesmo exemplo acima colocado, o preço que a empresa cobrará por cada cliente atendido, seja através da seguradora ou diretamente do consumidor final, deverá cobrir o que ela teve de custos com o enfermeiro coordenador; caso contrário, pode não ter lucro na atividade, ou, ainda, ter prejuízo.

Outros conceitos importantes são os de Gastos, Despesas e Perdas. Os gastos ${ }^{3}$ são entendidos como o sacrifício financeiro que a empresa arca para a obtenção de um produto ou serviço qualquer. Despesas ${ }^{3}$ correspondem ao bem ou serviço consumido direta ou indiretamente para a obtenção de receitas. Não estão associadas à produção de um bem ou prestação de um serviço. Como exemplo de despesas, podemos citar gastos com funcionários administrativos, ou seja, uma recepcionista. Necessitamos dela para que a empresa funcione, mas, por não estar ligada diretamente ao cliente final, 0 dono da empresa não pode cobrar por ela diretamente ao cliente. Podemos, então, apresentar a seguinte equação: gastos $=$ custos + despesas. Ainda, gastos ${ }^{3}$ podem ser temporariamente classificados como investimento e, à medida que forem consumidos, receberão a classificação de custos ou despesas. Tudo que não puder ser reposto pela cobrança ao cliente final serão as perdas. Então podemos dizer, por exemplo, que os gastos para a realização de um curativo incluem: (1) custos com materiais, como gaze, micropore, luva, soluções; (2) custo de pessoal, como enfermeiro; (3) despesa com um motorista de ambulância para levar o profissional até 0 domicílio do cliente. Ao cobrar do convênio, ou do cliente, por este procedimento, já estarão embutidos estes valores acrescidos de uma margem de lucro estipulada, geralmente para a empresa (35\% em média). Ou seja, estes valores, de alguma forma, serão repostos. Mas, se por acaso, houver a utilização de dois pares de luva, em vez de um par, e o convênio resolver que não irá pagar, quem arca com esta perda é a própria empresa. E, dependendo do valor e quantas vezes isto acontecer, pode haver prejuízo ou, no mínimo, não ter lucro. E sabemos que uma das estratégias de competição no mercado é a redução dos custos e das perdas. Ou seja, a empresa ${ }^{4}$ precisa operar com sucesso no mercado para conseguir sobreviver.

\section{A Gerência do Treinamento para o Cuidado no Domicílio - Quanto Custa Preparar Pessoal e Quanto Custa o Cuidado}

A Assistência Domiciliar ${ }^{1}$ é uma atividade complexa que exige do profissional conhecimento científico, experiência profissional, habilidade técnica e nas relações interpessoais para lidar com os outros membros da equipe multidisciplinar da saúde, fornecedores, auditores das seguradoras de saúde e, ainda, com a emoção e os valores dos clientes e familiares. 
Transformar todos estes requisitos em uma ação bem administrada é o segredo para o sucesso, ou fracasso, de uma empresa de assistência domiciliar. Inicialmente, o treinamento deve conter o planejamento de todo o atendimento e, em seguida, os conteúdos dos cuidados que serão realizados para o cliente desde o prognóstico médico, a meta a ser alcançada com a ação de cada profissional da saúde envolvido até a alta domiciliar. Todas as informações são passadas ao cliente e seus familiares, inclusive dos procedimentos a serem realizados pelos profissionais, pelo próprio cliente ou por algum membro da família. Ainda há a orientação sobre todos os materiais e equipamentos que serão utilizados durante a internação e, caso necessário, instruções sobre a utilização dos recursos.

A maioria das grandes empresas de assistência domiciliar no Brasil conta com uma equipe multiprofissional para a prestação de seus serviços, porém, aqui neste estudo, focalizaremos o trabalho realizado pelo enfermeiro coordenador-gerente de treinamento e distribuição do pessoal de enfermagem.

Independentemente do cargo ou função que ocupam, os enfermeiros que orientam o pessoal de enfermagem devem estimular a formação de um perfil básico para a realização deste tipo de serviço, que inclui: (a) capacidade em se adaptar às situações inesperadas; (b) criatividade para transformar seus conhecimentos de cuidado hospitalar em cuidados domiciliares; (c) saber estabelecer limites para seu trabalho (não se envolver com os problemas da família); (d) ser sensível e observador; (e) ter iniciativa e preparo técnico para situações de emergência; (f) saber trabalhar em equipe multiprofissional, ou seja, em prol de objetivos comuns onde seus conhecimentos específicos são complementares e não concorrentes entre si; (g) ter boa comunicação; (h) ter noções básicas de administração e finanças, assim como preparo para gestão de pessoas. Apesar de muitos destes tópicos estarem ainda longe dos conteúdos do aprendizado, não só do enfermeiro, torna-se necessário este investimento, à medida que cresce o uso de conceitos e práticas na ação de cuidar no domićlio.

Atualmente, no Brasil, poucos cursos contemplam esta área de conhecimento para a Enfermagem, existindo apenas alguns cursos de pós-graduação em Assistência Domiciliar que abrangem todos os tópicos mencionados, dentre outros de extrema importância que estão mais concentrados na região sudeste, como São Paulo, Rio de Janeiro e Minas Gerais. Assim, a Assistência Domiciliar é um grande campo a ser descoberto, que precisa, inicialmente, de preparo de pessoal, tanto na área do ensino superior quanto médio, além de ser urgente pesquisar a própria prática. Já está em desenvolvimento alguma pesquisa no domicílio, como é o caso do prontuário eletrônico, e acreditamos que muitos outros ainda estão por vir. No entanto, nossa atenção nesse momento se volta para a prática diária, quando cada vez mais nos surpreendemos com as descobertas e com os novos protocolos existentes. Talvez seja uma grande chance do enfermeiro começar a criar negócios próprios e conhecimentos próprios do saber cuidar, como é o caso de criar empresas próprias de cuidado. A prática de pensar cuidados de enfermagem ${ }^{5}$ para pessoas no domicílio é ensinar outros para o encontro entre a pessoa que é cuidada e a pessoa que cuida, estendendo sua ação inclusive para os prestadores de cuidados, ao trazê-los para junto de si, orientando-os em suas ações.
Estamos hoje, em nossa empresa, treinando pessoal para cuidar, caminhando novamente para uma assistência individualizada, na qual podemos implementar um cuidado diferenciado mais voltado para o atendimento da necessidade do SER HUMANO, que é único, singular e complexo. A Enfermagem ${ }^{6}$ tem como finalidade o cuidar/cuidado do ser humano, e cuidar da vida das pessoas exige os saberes científico e técnico, imbuídos da ética e do respeito necessário ao cuidado, o que vem ampliando o mercado de trabalho para a Enfermagem, além de oferecer a estes profissionais a possibilidade de adquirir novos conhecimentos.

A maioria das empresas de assistência domiciliar tem em seu quadro os enfermeiros que coordenam a atividade da Assistência Domiciliar, aquele que faz captação de clientes e internação domiciliar e os que supervisionam diretamente os cuidados, e algumas empresas contam também com um enfermeiro para realização da educação continuada. Cada qual com suas devidas funções, porém com objetivos bem definidos a serem atingidos, atentando para a qualidade desta assistência que deve ser prestada em forma de cuidado como ação direta.

Administrar cuidados à distância pode ser mais complexo e complicado, e, por isso, é preciso mencionar com clareza nas orientações quais são as atividades realizadas pelo enfermeirocoordenador da assistência domiciliar, que, com um regime extenso de horas de trabalho, não poupa esforços para cumprir seu papel, e informar que tais atividades requerem tempo e disponibilidade, dedicação exclusiva e grande competência técnica e administrativa. É importante destacar nos conteúdos de educação continuada estas atividades, (a) administração dos recursos técnicos e de materiais que são realizados através da organização e logística na distribuição dos mesmos; (b) administração da logística no que se refere à entrega de medicamentos, o que requer reposição e manutenção diária ou semanal; (c) saber administrar conflitos, talvez a atividade mais desgastante de todo o processo e que requer uma grande habilidade deste profissional. De uma maneira geral, o enfermeiro coordenador deve administrar e resolver conflitos de naturezas diversas já existentes ou que venham a surgir, de maneira que os prejuízos possam ser diminuídos, tanto para a empresa quanto para o cliente.

Uma outra importante função deste enfermeiro está no controle dos gastos da prestação de serviços. Como sabemos, a rede de Assistência Domiciliar Privada ${ }^{1}$ presta serviços, principalmente, a outras empresas de grande porte. Desta forma, o controle por parte da empresa de assistência domiciliar deve ser rigoroso, e quem geralmente o faz é o enfermeiro. Caso contrário, poderão existir perdas, que serão assumidas pela própria empresa.

\section{METODOLOGIA}

Por não existirem muitos trabalhos abordando o tema Administração de Cuidados Domiciliares, nosso estudo, objetivando contribuir para a área de Administração em Enfermagem, tem caráter de um relato de experiência, mostrando algumas atividades desenvolvidas por uma empresa que presta serviços para que sejam realizados os cuidados domiciliares. 0 estudo foi realizado no período de janeiro de 2004 a maio de 2005. Foram utilizados como base para a coleta de informações documentos existentes na referida empresa prestadora de serviços. Cabe mencionar que este 
trabalho obedeceu a todos os requisitos éticos exigidos para a sua elaboração e que a escolha de tal empresa se deve ao fato de uma das pesquisadoras ser sócia da mesma e responsável pelo treinamento e gestão dos prestadores de serviço na empresa de assistência domiciliar.

\section{RESULTADOS}

Os resultados foram trabalhados através de três categorias:

A) Estratégias de Recrutamento e Custo da Seleção dos Profissionais de Enfermagem para a Assistência Domiciliar;

B) Custos com o Treinamento do Pessoal Selecionado para Assistência Domiciliar.

C) Alocação dos Profissionais Treinados no Mercado de Cuidados Domiciliares e Particulares.

Os referentes à primeira categoria, denominada "Estratégias de Recrutamento e Custo da Seleção dos Profissionais de Enfermagem para a Assistência Domiciliar", são apresentados na Gráfico 1 e na Tabela 1. Cabe destacar que para o processo seletivo correspondente a 3 horas de duração, faz-se necessário a utilização de um enfermeiro, que tem como valor, para a sua hora de trabalho, $\mathrm{R} \$ 22,22$ (sendo sua remuneração total para 180 horas mensais o valor de $R \$ 4.000,00$ mensais).

\section{Gráfico 1:}

Demonstrativo de como é realizado o recrutamento dos profissionais e em que proporção eles ocorrem.

(Jan. 2004/maio 2005).

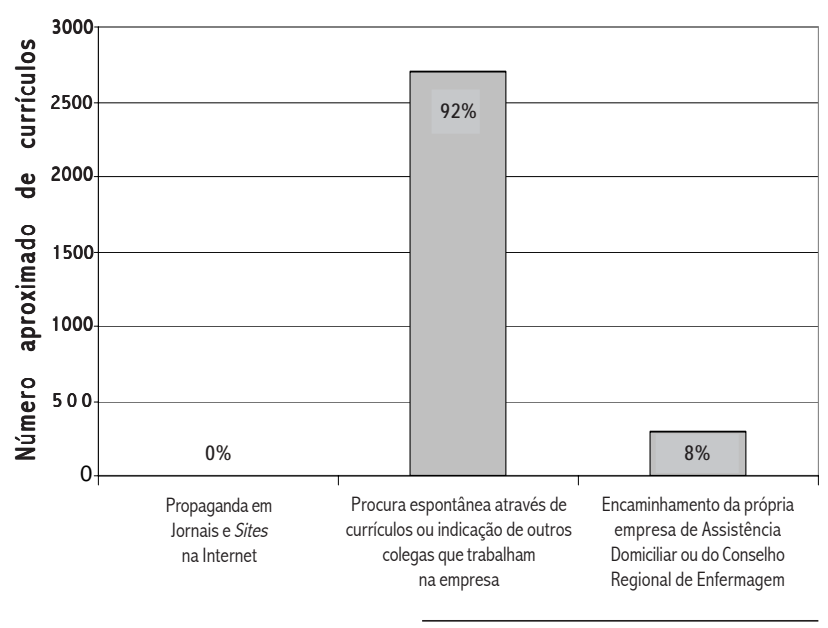

Tabela 1:

Valor médio do custo de seleção de profissionais para a assistência domiciliar. Foram um total de 29 processos seletivos no período, cada um com duração média de 3 horas. Número médio de participantes: 15 candidatos por seleção. Computado apenas o custo variável.

\begin{tabular}{l|c|c}
\hline Especificação & $\begin{array}{c}\text { Quantidade Média } \\
\text { Necessária por } \\
\text { Processo Seletivo }\end{array}$ & $\begin{array}{c}\text { Custo Médio } \\
\text { Necessário por } \\
\text { Processo Seletivo }\end{array}$ \\
\hline Profissionais Necessários: & 01 & $\mathrm{R} \$ 66,66$ \\
Enfermeiro & $(\mathrm{R} \$ 22,22 \times 3$ horas) \\
Material Utilizado: Papel & $2 \mathrm{fls} /$ candidato & $\mathrm{R} \$ 0,90$ \\
Energia Elétrica & 3 horas & $\mathrm{R} \$ 0,66$ \\
Telefone & 30 impulsos & $\mathrm{R} \$ 4,20$ \\
Lanche para o grupo & $01 /$ processo seletivo & $\mathrm{R} \$ 22,00$ \\
\hline Total & & $\mathrm{R} \$ 94,42$ \\
\hline
\end{tabular}

As Tabelas 2 e 3 abordam a segunda categoria, "Custos com o Treinamento do Pessoal Selecionado para Assistência Domiciliar". Vale mencionar que a hora trabalhada do enfermeiro e do gerente administrativo financeiro que participam do processo de treinamento é equivalente ao valor de $R \$ 22,22$

\section{Tabela 2:}

Demonstrativo do número de profissionais treinados ativos e inativos.

\begin{tabular}{l|c|c}
\hline Profissionais & Quantidade & $\begin{array}{c}\text { Percentual } \\
\mathbf{( \% )}\end{array}$ \\
\hline $\begin{array}{l}\text { Profissionais que } \\
\text { ficaram ativos }\end{array}$ & 52 & 19,12 \\
$\begin{array}{l}\text { Profissionais que } \\
\text { ficaram inativos }\end{array}$ & 224 & 80,88 \\
\hline $\begin{array}{l}\text { Total de } \\
\text { Profissionais } \\
\text { Treinados }\end{array}$ & 276 & 100,00 \\
\hline
\end{tabular}

\section{Tabela 3:}

Custo médio do treinamento de um total de 23 treinamentos realizados durante o período do estudo. Cada treinamento é composto de 2 dias, sendo a carga horária de $7 \mathrm{~h} /$ dia, num total de $14 \mathrm{~h}$ para cada treinamento de 2 dias. Em média 12 profissionais participam do treinamento (ou seja, o mesmo grupo participa nos 2 dias). Computado apenas custo variável.

\begin{tabular}{|c|c|c|}
\hline Especificação & \begin{tabular}{|c|} 
Quantidade Média \\
Necessária por \\
Treinamento
\end{tabular} & $\begin{array}{l}\text { Custo Médio } \\
\text { Necessário por } \\
\text { Treinamento }\end{array}$ \\
\hline $\begin{array}{l}\text { Profissional: } \\
\text { Enfermeiro }\end{array}$ & 02 & $\begin{array}{c}R \$ 311,08 \\
(R \$ 22,22 \times 14 h)\end{array}$ \\
\hline $\begin{array}{l}\text { Profissional Administrativo: } \\
\text { Gerente Financeiro } \\
\text { da Cooperativa }\end{array}$ & 01 & $\mathrm{R} \$ 66,66$ \\
\hline Aluguel de Sala & 2 dias & $\mathrm{R} \$ 71,38$ \\
\hline Material: Papel & $01 \mathrm{fl} /$ profissional & $R \$ 0,36$ \\
\hline Energia Elétrica & 14 horas & $R \$ 3,08$ \\
\hline Telefone & 24 impulsos & $R \$ 3,36$ \\
\hline Lanche para o grupo & 02/treinamento & $\mathrm{R} \$ 44,00$ \\
\hline Total & & $\mathrm{R} \$ 499,92$ \\
\hline
\end{tabular}

Por fim, as Tabelas 4 e 5 se referem à terceira categoria: "Alocação dos Profissionais Treinados no Mercado de Cuidados Domiciliares e Particulares".

\section{Tabela 4:}

Caracterização das instituições e alocação dos profissionais após treinamento.

\begin{tabular}{l|c|c}
\hline $\begin{array}{l}\text { Tipo de } \\
\text { Instituição }\end{array}$ & $\begin{array}{c}\mathbf{N}^{\circ} \text { Profissionais } \\
\text { Treinados e Alocados }\end{array}$ & $\begin{array}{c}\text { Percentual } \\
\text { (\%) }\end{array}$ \\
\hline Instituição Particular & 02 & 9,62 \\
Instituição Familiar & 50 & 90,38 \\
\hline Total & 52 & 100,00 \\
\hline
\end{tabular}




\section{Tabela 5:}

Preço médio do cuidar em cada tipo de instituição.

\begin{tabular}{l|c|c}
\hline $\begin{array}{l}\text { Categoria } \\
\text { Profissional }\end{array}$ & $\begin{array}{c}\text { Valor Médio da Hora } \\
\text { Trabalhada na } \\
\text { Instituição Particular }\end{array}$ & $\begin{array}{c}\text { Valor Médio da Hora } \\
\text { Trabalhada na } \\
\text { Instituição Familiar }\end{array}$ \\
\hline $\begin{array}{l}\text { Coordenador de } \\
\text { Enfermagem }\end{array}$ & $\mathrm{R} \$ 22,22$ & $\mathrm{R} \$ 16,67$ \\
$\begin{array}{l}\text { Enfermeiro da } \\
\text { Educação Continuada } \\
\text { Enfermeiro Supervisor }\end{array}$ & $\mathrm{R} \$ 22,22$ & $\mathrm{R} \$ 12,92$ \\
$\begin{array}{l}\text { Téc./Aux. de } \\
\text { Enfermagem }\end{array}$ & - & $\mathrm{R} \$ 12,92$ \\
\hline
\end{tabular}

\section{DISCUSSÃO E CONCLUSÃO}

Para a realização de uma adequada assistência domiciliar, faz-se necessário contar com bons profissionais de enfermagem, e, para que isso ocorra, deve-se, após o seu recrutamento e seleção, treiná-los adequadamente. Durante o período desse estudo, o recrutamento foi feito através de avaliação de currículos recebidos, através de anúncios colocados em jornais, indicação de outros profissionais que já trabalham na empresa, ou mesmo, procura espontânea por parte de profissionais que já trabalham na empresa (conforme é mostrado no Gráfico 1). Após essa etapa, foi realizado um processo seletivo para a escolha dos melhores profissionais de enfermagem designados para a realização da assistência domiciliar. 0 custo total dos 29 processos seletivos realizados no período do estudo foi de $\mathrm{R} \$ 2.738,18$ (sendo que o custo médio de cada processo corresponde ao valor de $R \$ 94,42$ ). A seguir, as pessoas aprovadas no processo passam por um treinamento no qual é feita uma capacitação para essa modalidade de trabalho. 0 custo total dessa etapa para 23 treinamentos (cada treinamento corresponde a dois dias, e cada dia, a sete horas; ou seja, cada treinamento corresponde a 14 horas) correspondeu ao valor de $\mathrm{R} \$ 11.498,16$, em que o custo médio por cada treinamento foi de $R \$ 499,92$. Percebemos, desta forma, que os custos destes processos são altos para o número de profissionais que permanecem ativos nas escalas da assistência domiciliar. Vale destacar que a assistência domiciliar conta com uma elevada rotatividade de internação/alta, na qual, muitas vezes, aqueles profissionais de enfermagem que foram escalados e cujos clientes tiveram alta permanecem inativos, ou seja, aguardando uma nova internação e, conseqüentemente, serem escalados para um novo cliente, daí o uso neste trabalho do termo inativo. Todos estes processos são desgastantes para os enfermeiros que os realizam e exigem deles tempo, conhecimento e preparo, para que tais atividades sejam realizadas com efetividade.

Os custos destes dois processos foram subestimados por nós neste trabalho, a partir do momento em que não incluímos os custos de bonecos de treinamento, equipamentos utilizados para a realização das palestras, como retroprojetor, projetor de slides, datashow, e suas respectivas depreciações. Mesmo assim, percebemos um valor alto para cada processo.

Como estamos percebendo, estes conhecimentos e informações sobre economia são pouco utilizados por nós no cotidiano do cuidar. Estamos mais preocupados em realizar os procedimentos técnicos e administrativos e, talvez por falta de tempo, até mesmo de uma visão mais abrangente, não voltamos nosso olhar para conceitos de tamanha importância. Nesta modalidade de assistência à saúde, o enfermeiro tem um papel fundamental no controle dos gastos. Percebam a importância de nosso trabalho. Desta forma, uma atividade desta dimensão não deveria estar valendo tão pouco em termos monetários, que, como vimos, varia em torno de $\mathrm{R} \$ 16,67 /$ hora (ver Tabela 5). Por que será que não começamos a buscar uma remuneração melhor para a classe? Acredito que precisamos estar buscando cada vez mais conhecimentos na área da economia e administração para estar discutindo, também, sobre estes nossos salários que, muitas vezes, não estão em perfeita harmonia com o que estamos realizando em nossa prática diária dentro das instituições de saúde e, agora, também, fora dela.

Esta é ainda uma experiência relativamente nova para os enfermeiros no que concerne a esta modalidade de trabalho, e estes conhecimentos sobre economia/administração poderiam estar dando um suporte para questionamentos ou análises. Mas, com certeza, existe um campo amplo e aberto para estas práticas diferenciadas, assim como um novo rumo em busca de mais autonomia pelo enfermeiro. Esta autonomia pode estar relacionada tanto ao cuidar individualizado para cada cliente quanto ao seu regime de trabalho. Quando nos referimos ao cuidado individualizado, estamos falando em prestar assistência a um único indivíduo, o que certamente não conseguimos fazer no hospital. Desta forma, podemos implementar nossos cuidados de enfermagem com mais autonomia e eficiência. Talvez assim possamos ter uma remuneração mais próxima do que consideramos ideal para nossa formação e atividade profissionais. Com o advento da assistência domiciliar, muitos postos de trabalho desaparecem, dando lugar à terceirização das estruturas de emprego. A globalização, surge, assim, como um caminho sem retorno, estimulando-nos a um novo olhar de assistência no tempo presente.

As dificuldades em administrar uma empresa de prestação de cuidados domiciliares são inúmeras e vão desde o custo com este processo até a manutenção destes profissionais de enfermagem na escala dos clientes por mais tempo. Tais dificuldades se devem ao fato de a situação das empresas de assistência domiciliar ser diferenciada das demais na medida em que a dinâmica de internação e rotatividade dos clientes é muito grande.

Se administrar já é considerado complexo na Enfermagem, por termos uma formação mais voltada para a área assistencial ${ }^{7}$, administrar à distância se torna ainda mais complicado, principalmente quando se trata de um ambiente que não é o hospitalar. Tudo tem que ser feito de forma a estar sempre envolvendo estes profissionais de enfermagem em atividades educacionais, de treinamento e comportamentais, pois é onde existem os maiores problemas nesta área de atuação. 
Para nós que participamos de todo este processo, apesar de ser muito desgastante, é, de certa forma, uma grande experiência e aprimoramento, pela troca de experiências e conhecimentos entre os indivíduos que dele participam. Tudo é diferente, desde o conhecimento técnico-científico até a atuação profissional na prática, que é muito rica. Na vida profissional da enfermeira ${ }^{8}$, o conhecimento é considerado valor

\section{Referências}

1. Silva FS. Manual do home- care. $2^{\mathrm{a}}$ ed. São Paulo (SP): Rimed; 2000.

2. Mendes JTG. Economia: fundamentos e aplicações. São Paulo (SP): Prentice Hall; 2004.

3. Bruni AL, Famá R. Gestão de custos e formação de preços. $3^{\mathrm{a}}$ ed. São Paulo (SP): Atlas; 2004.

4. Nellis J, Parker D. Princípios de economia para os negócios. São Paulo (SP): Futura; 2003.

5. Hesbeen W. Cuidar no hospital: enquadrar os cuidados de enfermagem numa perspectiva de cuidar. Loures: Lusociência; 2000.

6. Souza MF. Algumas reflexões sobre o conhecimento em enfermagem: Acta Paul Enferm 2004; 17 (3).

7. Martins VA, Nakao JRS, Fávero N. Atuação Gerencial do enfermeiro na perspectiva dos recém egressos do curso de enfermagem. Esc Anna Nery Rev Enferm 2006; abr 10 (1): 101-10.

8. Sautier J. A Globalização, a busca da identidade e suas conseqüências. Esc Anna Nery Rev Enferm; 2000; ago; 4 (2): 159 - 61. imprescindível. É o conhecimento que possibilita à enfermeira identificar e distinguir as necessidades de seus clientes, conhecer as aspirações de seu pessoal colaborador, considerar a capacidade desse pessoal, ministrar um cuidado individualizado, tomar uma decisão apropriada, fazer um julgamento criterioso, enfim, apresentar uma atitude coerente, fundamentando-se na verdade.

\section{Sobre as Autoras}

\section{Vivian Schutz}

Enfermeira, Doutoranda da Escola de Enfermagem Anna Nery da Universidade Federal do Rio de Janeiro.

\section{Joséte Luzia Leite}

Enfermeira-Orientadora, Professora Titular Emérita da Universidade Federal do Estado do Rio de Janeiro, Pesquisadora do CNPq.

\section{Nébia Maria Almeida de Figueiredo}

Enfermeira, Professora Titular e Doutora da Universidade Federal do Estado do Rio de Janeiro. 